\title{
STUDY OF THE SENSORLESS SWITCHED RELUCTANCE MOTOR CONTROLLER BASED THE SIMPLIFIED FLUX METHOD
}

\author{
TIAN Zhi-wei and ZHANG Yu-lin \\ ${ }^{1}$ School of Information Science and Engineering, University of Jinan, Jinan 250022, PR \\ China \\ 1065074293 @qq. com \\ ise_zhangyleujn.edu.cn
}

\begin{abstract}
Tradition of the simplified flux method has the characteristics of simple and quick, small memory, but it exists coupling when the phase switch. According to the basis of the simplified flux, the author creates a new method named the turn-on and turn-off simplified flux method. The method is based on fixed turn-on angle and turn-off angle as the prerequisite, and estimates on and off position of the sensorless switched reluctance motor. Under the environment of Matlab/Simulink, the method realizes the sensorless control of the switched reluctance motor.
\end{abstract}

\section{KEYWORDS}

switched reluctance motor, sensorless detect, the simplified flux method, the turn-on and turn-off simplified flux method, control.

\section{INTRODUCTION}

The application of Switched Reluctance Motor (SRM) emerged in the 1980s in industry, the Switched Reluctance motor Drive system (SRD) as a new type of speed regulation drive system, has not only low cost, high efficiency, simple structure, flexible control and the advantages of excellent speed regulating performance, but also the advantages of ac speed regulation system and dc speed regulating system. At present, the motor has been successfully used in general industry, textile machinery, electric drive and household appliances and other industrial fields [1]. Position detection is the basis of the operation of SRD, and it is the first condition to ensure the SRM with good performance. In actual application, SRM generally used an optical or magnetic sensitive shaft position sensor as the position detector. And the detector with the location has not only increased the size and cost of SRM, also reduced its reliability and robustness, SRM cannot fully play its advantages. So, to eliminate the position sensor and to realize the sensorless detection technology is the hot spot of SRM research.

Scholars at home and abroad began to research no position detection technology from the early 1980s, over the past three decades, international scholars put forward different position detection technologies, which roughly included the opening phase test, non-opening phase test, additional components test, intelligent control test[1-4]. Literatures [7] summarized some sensor-less rotor position detecting methods of SRM. The main methods are pulse injection method, simplified flux method[8], intelligent control method[9-10] and so on. Here, on the basis of 
simplified flux method, a new method named the turn-on and turn-off simplified flux method is founded in the paper, and adding the control strategy, SRM realizes control of sensorless.

\section{SIMPLIFIED FLUX METHOD}

In 2001, Qiu Yihui, Zhan Qionghua, the Chinese scholars, put forward the simplified flux method, this method is based on flux. Its basic idea is: when SRM takes turns turning on the phase in single-phase, it is only the rotor position information of commutation, not the rotor position information of each moment that is judged, in other words, only the rotor position information of turn-on and turn-off needs judging. That is to say, when SRM works, it obtains the estimated flux by integrating, the reference flux corresponds to the flux of current commutation position. The estimated flux and the reference flux are compared. If the former is smaller than the latter, it is not the time to commutate, the current phase continues turn-on, with the rotation of the rotor, the former will be bigger than the latter, it is the time to commutate, so turn off the current phase and turn on the next phase immediately[5].

Simplified flux method works under the condition that SRM takes turns turning on the phase in single-phase and uses current chopping control. On this condition, SRM not only realizes the sensorless detection technology by judging the position of commutation, but also makes the estimated winding flux more accurate without the influence of mutual inductance[6]. Figure 1 is SRM control system principle diagram using simplified flux method.

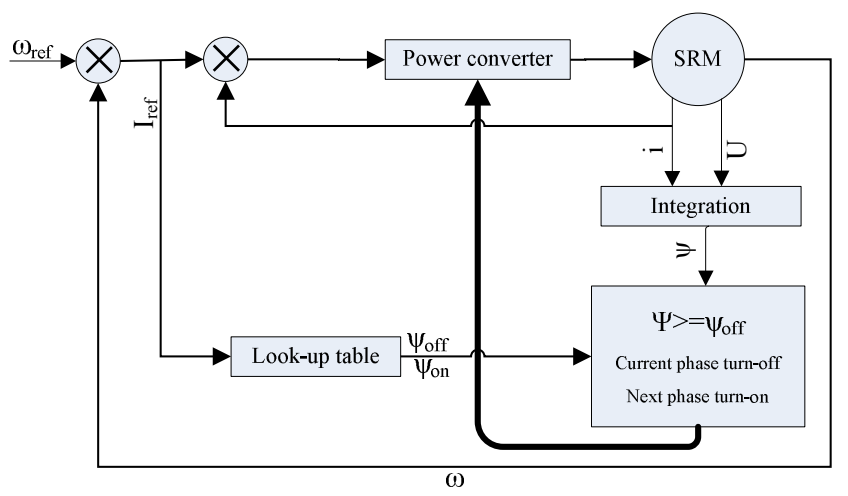

Figure 1. SRM control system principle diagram using simplified flux method

Values of the reference flux are generally equal to the values of its turn-off, and SRM generally turns off some phase on the condition that winding inductance value gets maximum[6]. So just test and store the flux-current curve of max winding inductance value. According to the curve, look up table and get the flux of max winding inductance value, and then multiply the value by a coefficient that is not greater than 1 to get the reference flux values of commutation.

\section{TURN-ON ANd TURN-OFF SimplifiEd FLUX METHOD}

Although simplified flux method is simply, quickly, small footprint and no additional hardware, it will cause the coupling between the windings if SRM turns off the current phase at the same time turns on the next phase. In the practical operation of SRM, turn-on and turn-off should have a certain time interval.

Considering the deficiency of simplified flux method, based on the simplified flux method, the turn-on and turn-off simplified flux method is proposed. It is based on fixed turn-on angle and 
turn-off angle, if the flux value of the current phase is greater than the reference turn-off flux value, turn off the current phase, and only the flux value of next phase is greater than the reference turn-on flux value, do turn on the next phase. Figure 2 is SRM control system principle diagram using turn-on and turn-off simplified flux method.

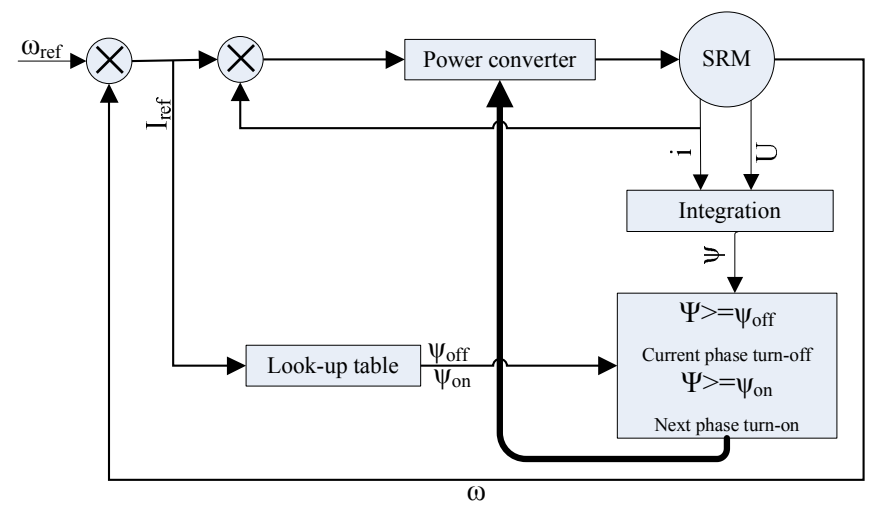

Figure 2. SRM control system principle diagram using turn-on and turn-off simplified flux method.

\section{Simulation AND ANALYSIS}

\subsection{SRM Model}

Matlab version, Matlab R2012a, is used as the simulation tool, Simulink of it includes the SRM mo-del, this model is very accurate. Based on the model, the sensorless detection technology is studied. The technical parameters of SRM are 3 phases with 6 stators and 4 rotors, rated power of $60 \mathrm{KW}$, rated speed of $2500 \mathrm{r} / \mathrm{min}$.

\subsection{Obtain Flux}

Due to the influence of mutual inductance between phases to the SRM is very small, for facilitating analysis, mutual inductance of phases is commonly neglected in the process of computing flux. The reference flux can be obtained from the following formula:

In own SRM model, flux is obtained in the same way. For convenience, the output flux of SRM model is directly used, while flux access model no longer needs setting up. Reference flux is obtained from two-dimensional tables of SRM model.

\subsection{Simulation of Simplified Flux Method}

According to the ideas of simplified flux method, figure 3 is a simulation model of SRM control system using simplified flux method, the system is controlled by double closed loop control that the outer loop is speed control, the inner loop is current control. 
Electrical and Electronics Engineering: An International Journal (ELELIJ) Vol 4, No 4, November 2015

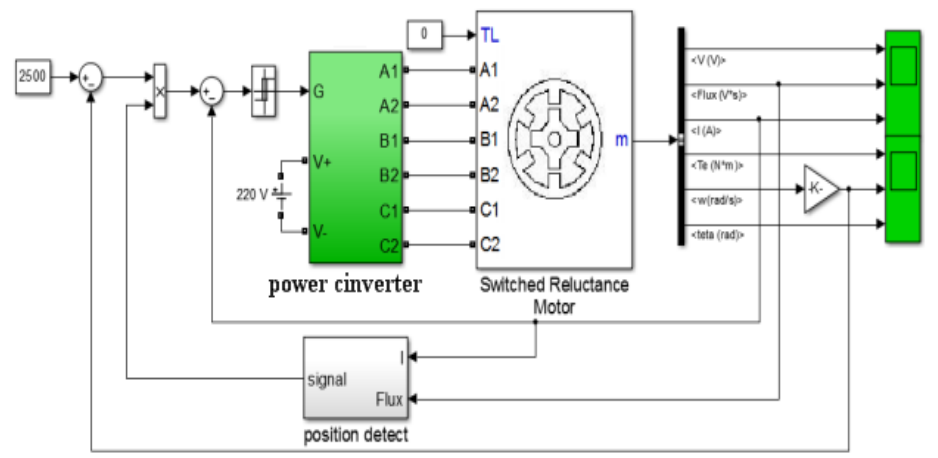

Figure 3. A simulation model of SRM control system using simplified flux method

When the load is 0 , and the preset speed is $1500 \mathrm{r} / \mathrm{min}$, the simulation waveform is shown as figure 4.

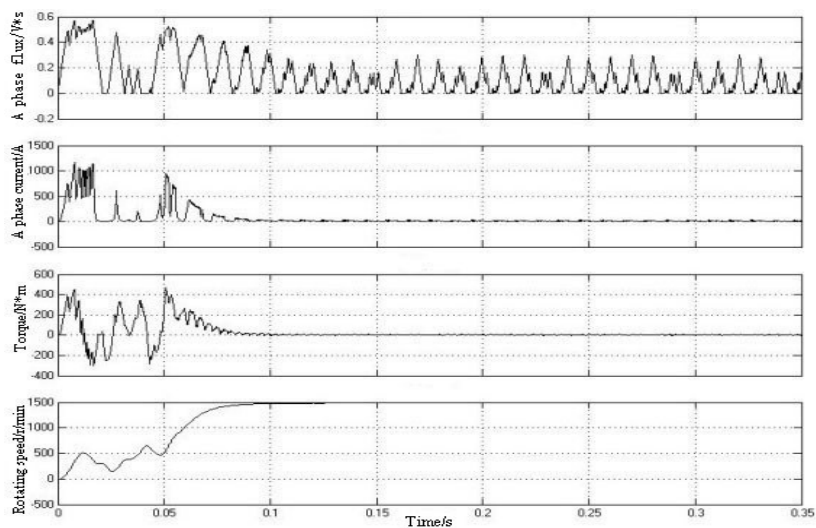

Figure 4. The simulation waveform of the load is 0 , and the preset speed is $1500 \mathrm{r} / \mathrm{min}$

From figure 4, SRM control system using simplified flux method reaches the preset speed, realizes the sensorless control of SRM. Due to the current phase turn-off together with the next phase turn-on, changes of the flux waveforms are not stable, and the speed of SRM slows down in the speed-up stage.

\subsection{Simulation of Turn-on and turn-off Simplified Flux Method}

The simulation model of SRM control system using turn-on and turn-off simplified flux method is similar to the one using simplified flux method. The difference is the module location selection, figure -5 is the internal structure of location selection module.

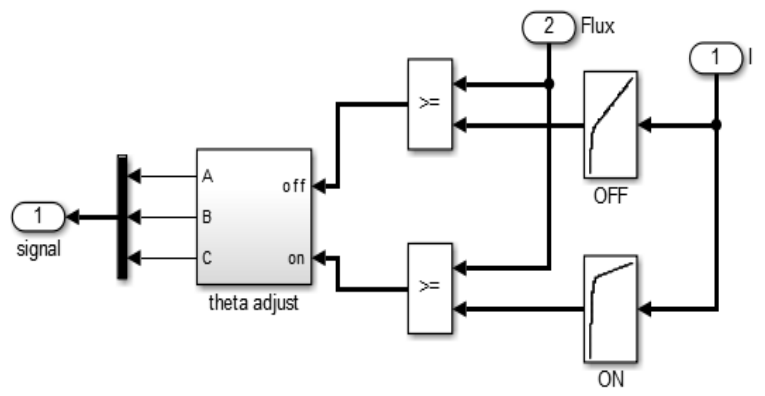


Figure 5. The internal structure of location selection module.

When the load is 0 , and the preset speed is $1000 \mathrm{r} / \mathrm{min}$, the control system can achieve better control of the SRM. Its speed simulation waveform is shown as figure 6. Figure 7 is a steady-state simulation waveform. When the preset speed is set to other values, the control system can also achieve control of the SRM, the simulation waveform is similar to figure 6 and figure 7 , so, no longer list.
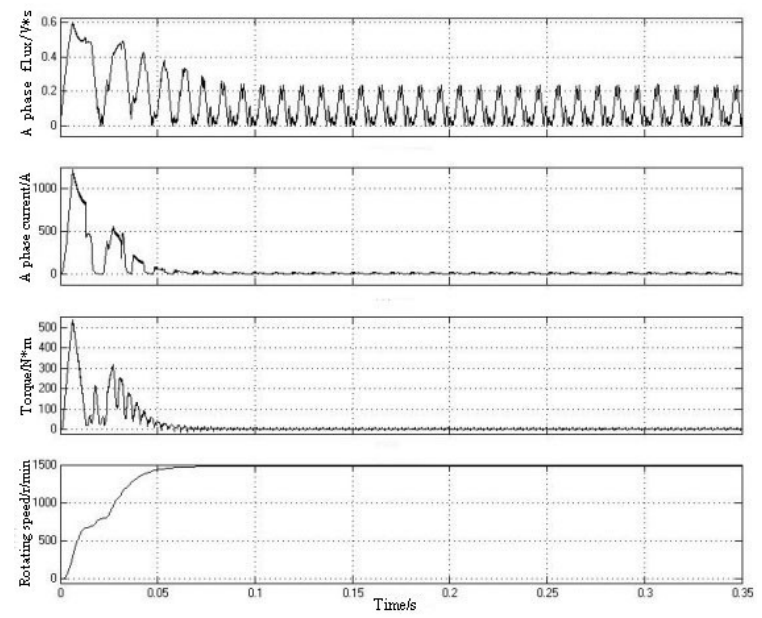

Figure 6 . The speed simulation waveform of the load is 0 , and the preset speed is $1500 \mathrm{r} / \mathrm{min}$
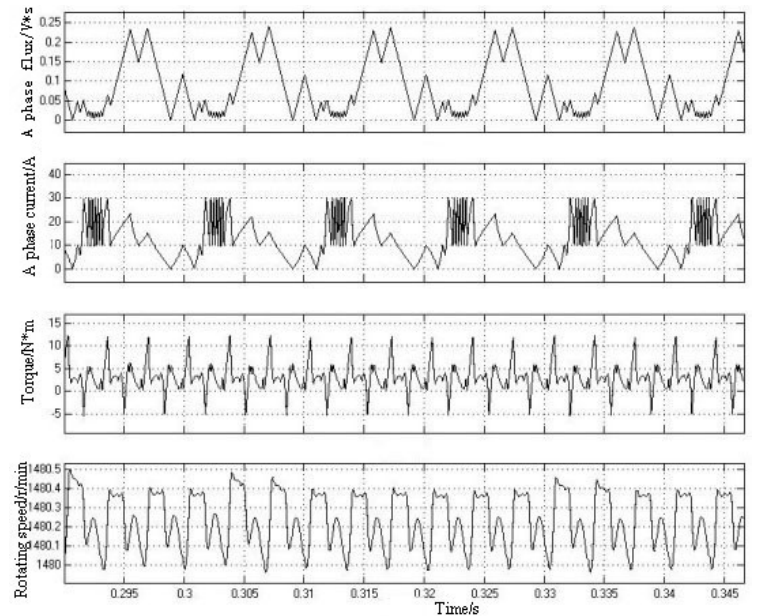

Figure 7. A steady-state simulation waveform

From figure 6, SRM control system using turn-on and turn-off simplified flux method reaches a desired preset speed. In addition, it takes less time, has stable changes of the flux waveforms, the speed-up stage is relatively smooth, and it overcomes the faults of two phases coupling using simplified flux method. From figure 7, SRM in the steady-state has smaller fluctuation, but the error between with the preset speed is larger (about $20 \mathrm{r} / \mathrm{min}$ ), and the speed volatility is not stable. SRM control system using turn-on and turn-off simplified flux method is not precise enough under the condition of no-load. 


\subsection{Simulation of Control Strategy}

In order to realize sensorless control technology of SRM more accurately, the outer loop speed PI and the inner loop current PI control strategy is selected, the control system diagram is shown as figure 8 .

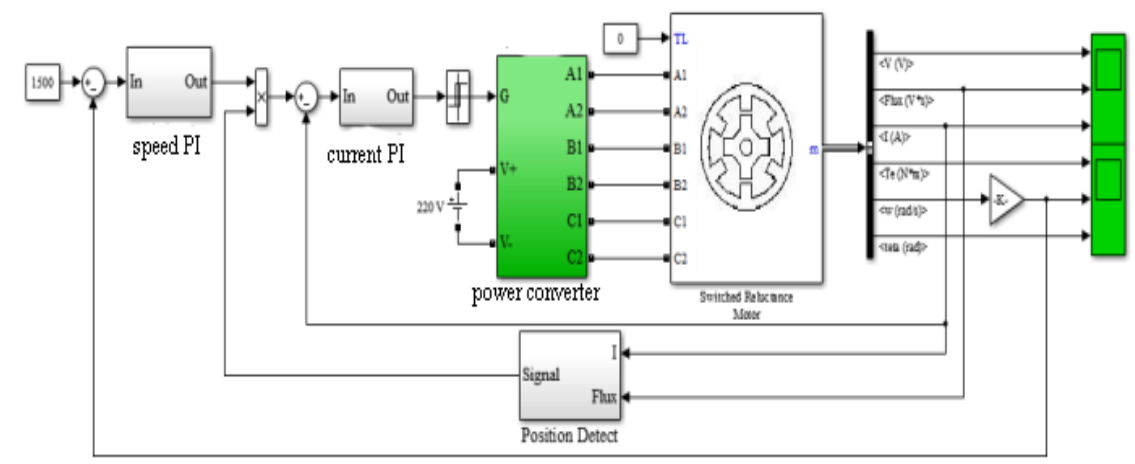

Figure 8. The control system using the outer loop speed PI and the inner loop current PI control strategy

When the load is 0 , and the preset speed is $1500 \mathrm{r} / \mathrm{min}$, the simulation waveform in steady-state is shown as figure 9 . When the preset speed is set to other values, the control system can also achieve control of the SRM, the simulation waveform is similar to figure 9, so, no longer list.
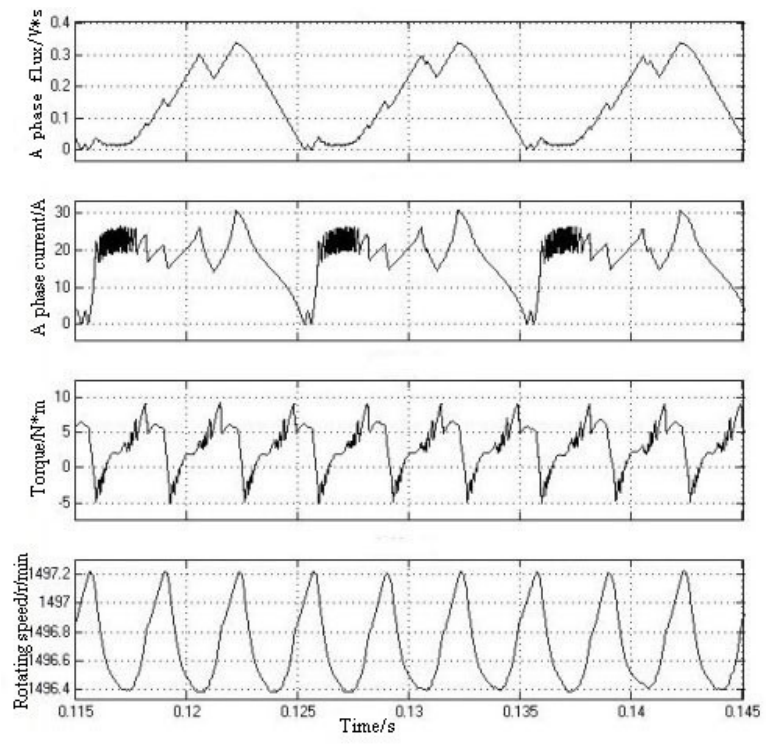

Figure 9. The simulation waveform in steady-state adding the control strategy

Compared figure 9 with figure 7, after adding the control strategy, the SRM volatility of flux, phase current, torque and speed is relatively stable in steady-state, the speed error to the preset speed is very small (about $3 \mathrm{r} / \mathrm{min}$ ), and the volatility of speed is smaller. So after adding the control strategy, the control system using turn-on and turn-off simplified flux method is more stable and accurate at no-load. 
In order to verify the operation and dynamic response of the control strategy with the load, two stages are divided as the following:

Stage 1: SRM starts, adds the load with $50 \mathrm{~N} . \mathrm{m}$, and the preset speed is set to $1000 \mathrm{r} / \mathrm{min}$ in the initial state. The steady-state simulation waveform of SRM is shown as figure -10.From figure 10, when the SRM reaches steady-state under load conditions, the volatility of flux, phase current, torque and speed is stable, the speed error to the preset speed is not big, and the volatility of speed is stable. So, after adding the control strategy, the SRM control system using turn-on and turn-off simplified flux method is more stable and accurate.
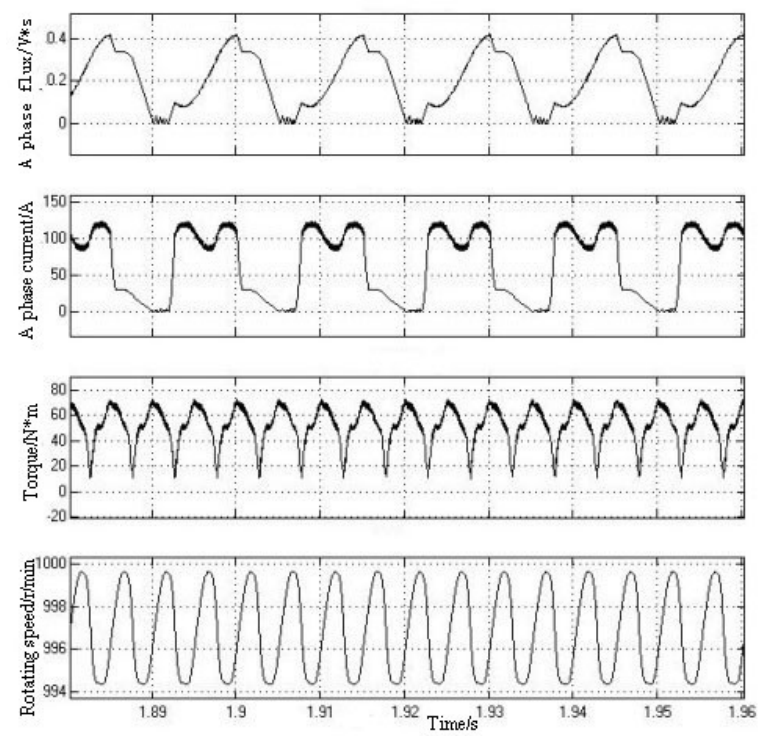

Figure 10. The simulation waveform of the 50N.m load and 1000r/min speed

Stage 2: based on satge1, adjust the preset rotation speed to $1500 \mathrm{r} / \mathrm{min}$. The steady-state simulation waveform of SRM is shown as figure 11.
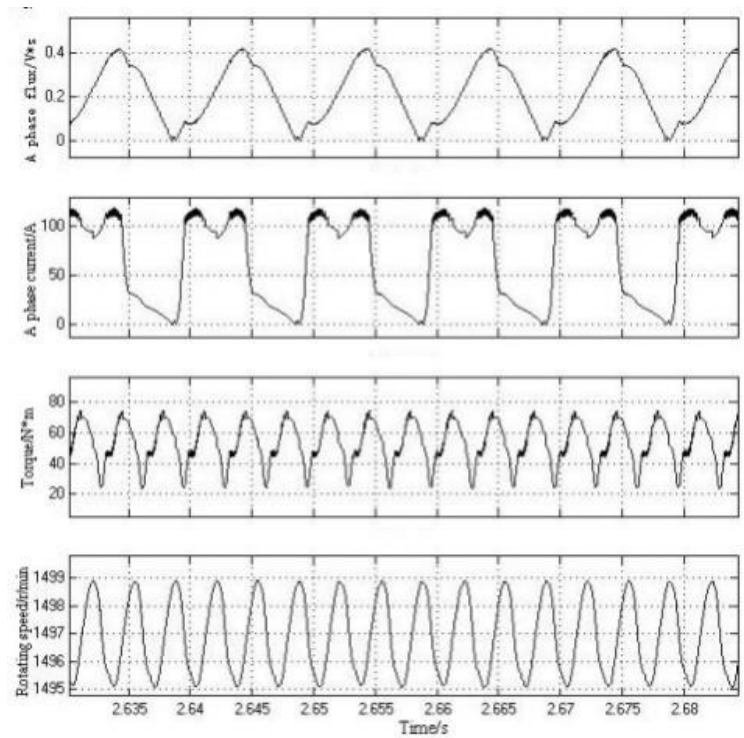

Figure 11. The simulation waveform of the $50 \mathrm{~N} . \mathrm{m}$ load and $1500 \mathrm{r} / \mathrm{min}$ speed 
From figure 11, when the SRM reaches steady-state under load conditions, the control system can also realize the control of the SRM by adjusting the preset speed. As reaching the steady state again, the control system has the same accuracy and stability.

\section{CONCLUSION}

Based on the simplified flux method, turn-on and turn-off simplified flux method is proposed, the method can realize the position detection better, it not only has the advantages of simplified flux method, but overcomes the existing coupling with phase commutation. Based on the method, SRM realizes the sensorless control using the outer loop speed PI and the inner loop current PI control strategy. What's more, it has relatively high accuracy and stability.

\section{REFERENCES}

[1] Wu Hong-xing,(2010) "Switched Reluctance Motor System Theory and Control Technology",China Electric Power Press, pp1-2.

[2] J.L.Duarte, A.Van Zwam \& C .Wijnands,(1999) "Reference Frames Fit for Controlling PWM Rectifier",IEEE Transactions on Industrial Electronics, Vol. 46,No.3,pp628-630.

[3] Min-Huei Kim \& Won-Sik Baik,(2007) “A Position Sensorless Control System of SRM over Wide Speed Range", The 7th Conference on Power Electronics,pp640-643.

[4] M.Malinowski \& F.Blaabjerg,(2001) "Virtual-flux-based Direct Power Control of Three Phase PWM Rectifiers", IEEE Transactions on Industry Applications,Vol. 37,No.4, pp1019-1027.

[5] LONG Hongyu \& CHENG Xiaohua,(2001) "Overview of Mechnical-sensorless Control Techniques of Switched Reluctance Motor”,MICROMOTORS,Vol. 44,No.9,pp71-74.

[6] QIU Yihui, ZHAN Qionghua \& MA Zhiyuan, GUO Wei,(2001) "The Indirect Position Sensing of SRM on the Basis of Simplified Flux Method", Proceedings of the CSEE,Vol. 10,pp60-63.

[7] WU Hong-xing, NI Tian, GUO Qing-bo \& YE Yu-jiao,(2011) "Summary of Detecting Rotor Position Technique for Switched Reluctance Motors",MICROMOTORS, Vol. 44,No.3,pp78-83.

[8] ZHANG Lei, LIU Chuang, WANG Yun-lin \& ZHANG Yun-long,(2013) "sensor-less technology of switched reluctance motor based on the improved simplified flux method",Electric Machines and Control,Vol. 17,No.11,pp13-19.

[9] ZHOU Su-ying \& LIN Hui,(2001) “Adaptive Sliding Mode Control for Switched Reluctance Motors Based on RBF Neural Network",Micro \&special motor, Vol. 55,No.7,pp57-76.

[10] NGUYEN Xuantruong, WANG Honghua \& NGUYEN Vietngu,(2012) "MPPT based on fuzzy control technology for wind power system with switched reluctance generator", Electric Power Automation Equipment, Vol. 32,No.5,pp129-132.

\section{Authors}

TIAN Zhi-wei (1990- ), male, master, research on switched reluctance motor, the design and application of embedded system.

ZHANG Yu-lin (1972- ), corresponding author, male, professor, the research direction for embedded system, computer architecture. 